\title{
A CONSTRUÇÃO DO ÊTHOS DE ORADOR NAS SÁTIRAS DE JUVENAL
}

\author{
Rafael Cavalcanti do Carmo* \\ Universidade Federal do Espírito Santo
}

\begin{abstract}
Resumo. O trabalho parte da ideia de que a sátira latina, por constituir-se em enunciação poética marcadamente pessoalizada, bem como pelo seu propósito moral de censura ao vício, guarda semelhanças com o discurso do orador. Dessa forma, tal qual ocorre na prática oratória, a sátira demanda a construção de uma voz enunciadora que, em Juvenal, se aproxima e se afasta do êthos que o orador constrói para si em seu discurso. O trabalho discute tal procedimento, associando-o à pertinência do riso como elemento integrante da sátira como gênero poético.
\end{abstract}

Palavras-chave. Juvenal; sátira latina; voz poética; riso.

D.O.I. 10.11606/issn.2358-3150.v19i2p80-89

Florence Dupont (1997), AO Discutir, EM UM ARTigo integrante do volume The Roman cultural revolution, o fenômeno da recitatio como condicionante de uma reorganização do espaço do discurso público na Roma Imperial, lembra-nos de que a oratio, na República Romana, "constitui um meio pelo qual o cidadão ideal encena e confirma seu status ou dignitas no interior da hierarquia sociopolítica do estado". ${ }^{1}$ Para o homem nobre romano, prossegue a autora, "a oportunidade de usar a linguagem dessa forma e, assim, ganhar acesso a honras elevadas é a essência da libertas". ${ }^{2}$

Em seu estudo sobre a sátira hexamétrica latina, Kirk Freudenburg (2001) tem como principal propósito construir argumentos que sustentem uma leitura capaz de esquivar-se da abordagem usual de tal gênero poético: aquela que encontra nas metáforas implicadas na nomeação mesma do gênero ${ }^{3}$ um elemento de unificação das diversas manifestações da sátira

\footnotetext{
Mestre em Letras na área de Literaturas Clássicas pela Universidade Federal do Espírito Santo (2014).

" Artigo recebido em 05.set.2016 e aceito para publicação em 25.out.2016.

${ }^{1}$ Dupont 1997, 44.

${ }^{2}$ Dupont 1997, 44.

${ }^{3}$ Sobre as implicações que o nome latino satura tem para a conotação da mistura como traço definidor da sátira como gênero poético autônomo, ver o artigo de Hansen (2011), intitulado "Anatomia da sátira", bem como o estudo "Musa pedestre", de Mario Citroni (2010).
} 
ao longo da história de sua produção em Roma. O autor privilegia uma leitura que, em suma, traça um caminho diverso em relação àquela segundo a qual o traço essencial da sátira latina é precisamente a variação advinda da admitida acanonicidade do gênero, causadora de dificuldades às leituras crítico-descritivas que dele se façam.

A fim de levar a cabo sua proposta, Freudenburg aproxima-se das transformações por que passa a sátira latina à medida que é desenvolvida por cada um dos poetas que a ela se dedicaram, negando a ideia de que as aproximações e os afastamentos - mais ou menos radicais - de cada satirista em relação a Lucílio sejam decorrentes apenas de ajustes genéricos operados pelos poetas, numa poesia definida menos pelo que é do que por aquilo que não é. Para o autor, a diversidade das experiências poéticas que dão corpo ao que hoje conhecemos como sátira hexamétrica latina se deve ao fato de ser o traço unificador do gênero uma questão que concerne essencialmente à construção de uma identidade romana republicana, a qual, argumenta, Lucílio não apenas influenciou em grande medida como simbolizou, e cujo fundamento era precisamente a noção de libertas. ${ }^{4}$ Tendo esse pressuposto como ponto de partida de sua leitura do gênero, Freudenburg desloca do campo restritamente retórico-poético as mudanças de foco e tom percebidas pelo leitor da sátira latina, tratando-as também, ou mesmo principalmente, como fruto da ciência, por parte dos satiristas pós-lucilianos, do embargo representado pela conjuntura em que produzem à performação da libertas republicana, bem como da exploração eficaz das possibilidades que novas dinâmicas socioculturais ofereciam ao cultivo da sátira.

Ainda que uma série de outros argumentos concorram com as causas extra-poéticas que Freudenburg aponta para a diversidade das manifestações da sátira latina, ${ }^{5}$ a centralidade que o autor confere à noção de libertas para o estabelecimento da sátira, conforme o operou Lucílio, parece ponto importante para a compreensão de uma característica marcante do gênero: sua aproximação em relação à oratio. Isso porque, segundo o mesmo Freudenburg, na introdução ao Cambridge companion to Roman satire, ${ }^{6} \mathrm{o}$ ataque pessoal franco e a crítica social, traços, segundo os críticos, distintivos da sátira luciliana e diretamente implicados na relativa fixação de um programa do gênero, constituíam um tipo de transposição, para o espaço da

\footnotetext{
${ }^{4}$ Freudenburg 2001, 3-4.

${ }^{5}$ Argumentos como a introdução, já em fins da República, dos modos poéticos alexandrinos ao gosto romano, a qual conduz, em Horácio, à crítica a Lucílio e à adoção de certo refinamento que, para o poeta augustano, faltou a seu antecessor; ou o impacto de uma educação oratória imperial, sentido em maior ou menor medida nas sátiras de Pérsio e Juvenal.

${ }^{6}$ Freudenburg 2005, 5.
} 
poesia, de ocasiões pragmáticas nas quais o cidadão romano performava o exercício de sua libertas.

Também é importante que se destaque, como o fez Mario Citroni (2010), além de um programático realismo da sátira luciliana - no sentido em que a poesia se comunica de maneira algo imediata com a realidade empírica - o impacto de uma enunciação poética personalizada, num âmbito romano de gêneros poéticos que, até então, primavam pela impessoalidade. Tal impacto poder-se-ia sentir de ao menos duas formas distintas, ambas diretamente implicadas na maneira como possivelmente tenha se efetivado a recepção da sátira luciliana: em primeiro lugar, a centralidade do que se diz na figura de um "eu" que o diz, apoiada por afirmações metapoéticas de sinceridade, poderia impulsionar a confluência objetiva entre a voz e a pessoa empírica do poeta; em segundo, tal fenômeno, por situar uma voz em primeira pessoa como sujeito daquilo que se enuncia, demanda a construção poético-retórica dessa voz enunciadora, impulsionando que se leia tudo quanto diga numa relação de interdependência com a construção de seu caráter.

Dessa forma, fundamenta-se, na sátira latina, a partir de Lucílio, a longeva questão dos limites entre um eu poético biográfico e um eu poeticamente engendrado em acordo com preceitos de decoro relativos aos diversos gêneros. Fato é que, biográfica ou artificiosa, a enunciação personalizada constrói o êthos da voz que a efetiva e que, no caso da sátira luciliana (e sua posterior, em maior ou menor medida), o procedimento da censura pungente ao que se considera vício constrói como homem virtuoso o agente dessa censura. Semelhantemente ao vitupério na retórica, em que, mirando o bem comum, o orador expõe seu alvo, por meio de ataques pessoais, como homem inimigo do que é moralmente bom, o eu poético da sátira luciliana, no campo da poesia, encena o que parece ser simultaneamente dever e direito do cidadão romano, ao construir-se como homem bom porque apto a atacar os maus.

No entanto, séria como possa soar a crítica a comportamentos desviantes do moralmente cabível a uma romanidade republicana, e não obstante ela seja feita - e aqui destacamos Juvenal - com severidade semelhante à do vitupério retórico, a sátira, por privilegiar entre seus temas a censura a comportamentos típicos da parte baixa do ânimo, como gênero aristotelicamente baixo, portanto, associa-se diretamente ao cômico. ${ }^{7}$ No entanto,

\footnotetext{
Se, para Aristóteles, a poesia é essencialmente imitação (Arist. Po. 1447a), três serão os critérios a distinguir os diferentes tipos de poesia: os meios por que imitam, os objetos que imitam, bem como a maneira como os imitam. Aristotelicamente, a classificação de um gênero como pertencente à esfera do cômico se dá pelo segundo desses critérios, isto é, os objetos da imitação. Serão cômicos, portanto, aqueles gêneros que se componham a partir da imitação das deformidades do ânimo, as quais podem ser simplesmente risíveis, ou mesmo causar sentimentos mais fortes como o horror e a repulsa.
} 
conforme nos diz o mesmo Hansen (2011, 151), nem todo cômico produz-se com a finalidade de suscitar o riso, a leitura da sátira, feita quer por antigos, quer por modernos, deixa dúvidas sobre a questão da pertinência, ou não, do riso como um efeito pretendido pelo gênero poético e, assim, integrante de seu programa.

Tal questão, de grande interesse aos propósitos deste texto, encontra já em Horácio um ponto relevante de reflexão. Importam-nos especificamente, aqui, as sátiras em que o poeta teoriza, por assim dizer, sobre a composição no gênero, unindo artifício poético a determinado didatismo ${ }^{8}$ em relação a um público que se via diante de uma filiação genérica à sátira, cujo produto, no entanto, em muito contrastava com a poesia do modelar Lucílio. Já no poema 1.4, Horácio lança luz sobre nossa questão, ao afirmar ser toda a poesia luciliana diretamente dependente da comédia grega arcaica, de modo que todo o trabalho do poeta latino teria sido o de adaptar a cadência dos versos:

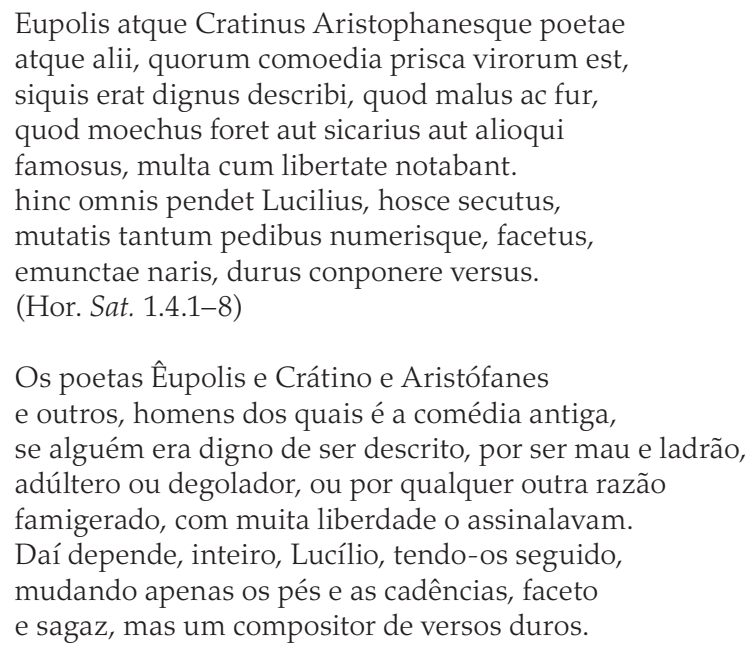

A associação direta entre a poesia luciliana e comédia antiga, ainda que restrita, na sátira 1.4 de Horácio, à questão da liberdade com que se ofende a outrem em ambas as manifestações poéticas, nos levaria, por si,

${ }^{8}$ Com o termo se quer dizer que Horácio, ainda que faça concessões honrosas a Lucílio, inventor do gênero poético a que se filia, tematiza, nas sátiras 1.4 e 1.10, os momentos de produção e recepção da sátira, como que para moldar o ato receptivo da audiência às mudanças que os Sermones propõem em relação à poesia luciliana.

${ }^{9}$ A exploração desses contrastes por Horácio é elucidativamente discutida por Freudenburg (2001, 15-124), ao longo de toda a seção de sua obra dedicada às sátiras de Horácio. 
à assunção da existência de efeitos comuns pretendidos tanto por Lucílio quanto pelos comediógrafos cujas obras lhe teriam servido de base. Pois quem negaria que a comédia grega arcaica tinha o riso como um dos efeitos de sua composição e encenação? Se vale o juízo, não pouco tendencioso, de Horácio, segundo o qual todo o Lucílio dependeria desses gregos, não estaria o riso indissociavelmente implicado também na sátira luciliana? O mesmo poeta dos sermones, em passagem igualmente importante, nos poupa o risco de incorrer em conclusões precipitadas. Quando, na sátira 1.10, Horácio reafirma o juízo anteriormente enunciado sobre Lucílio, marcando novamente o caminho diverso por que optou seguir na prática do gênero, ressalta encontrar qualidades na poesia do predecessor. Tal passo se encontra desenvolvido nos seis versos de abertura do poema:

Nempe incomposito dixi pede currere versus

Lucili. Quis tam Lucili fautor inepte est

Ut non hoc fateatur? At idem, quod sale multo

Urbem defricuit, charta laudatur eadem.

Nec tamen hoc tribuens dederim quoque cetera; nam sic

Et Laberi mimos ul pulchra poemata mirer.

ergo non satis est risu diducere rictum

auditoris; et est quaedam tamen hic quoque virtus.

(Hor. Sat. 1.10.1-8)

De fato eu disse correr mal elaborado o verso

de Lucílio. Quem tão tolo fã de Lucílio

não o confesse? Mas o mesmo, porque com muito sal

a cidade esfregou, é louvado na mesma folha.

Mas não por concedê-lo desisto do resto; pois assim,

mesmo os mimos de Labério, como belos poemas admirarei.

Não basta, pois, com riso abrir largas bocas

da audiência, ainda que haja aí certa virtude.

É grandemente relevante, aqui, ressaltarmos a causa por que, nos escritos de Horácio, Lucílio é louvado, expressa na subordinada quod sale multo urbem defricuit (Sat. 1.10.3-4), em razão da associação cultural da palavra sal, no mundo romano, à licenciosidade ou à ausência de gravidade e, por extensão, ao bom humor..$^{10} \mathrm{Ou}$ seja, Lucílio é admirado porque sua poesia faz rir. Os versos imediatamente posteriores desenvolvem ainda

${ }^{10}$ Marques Júnior $(2008,6-28)$ na introdução à sua tradução dos tratados que Cícero e Quintiliano dedicaram ao estudo dos efeitos retóricos do riso e da prescrição do uso desse expediente por parte do orador aponta a pertinência da palavra sal para descrever o gracejo. A poesia igualmente se utiliza dessa conotação, como se pode ver já em Catulo 17.6, que inclusive associa sal a lepor, ao defender a separação entre a vida casta do poeta e a permitida - e mesmo valorizada - jocosidade de seus versos. 
mais explicitamente essa ideia, ao mesmo tempo em que deixam claro o elemento que Horácio pretende adicionar à sátira e que o distinguirá de seu mestre: a elaboração. A comparação com os mimos, principalmente quando reforçada pela leitura de "sale", no contexto, é decisiva para a reafirmação do juízo horaciano sobre a qualidade apenas relativa da poesia de Lucílio: o satirista republicano tem graça, mas carece de elaboração artística. Diretamente interessante para nós é o fato de que Horácio, na leitura que faz de Lucílio, conta o riso como elemento pertencente à poesia de seu antecessor e, dessa forma, também ao gênero poético, ainda que este, ao longo de seu cultivo, pareça ter comportado diversos tipos de riso.

Se também o riso é ponto de toque entre a comédia grega arcaica e a sátira luciliana, resta-nos ressaltar o ponto mais importante da distinção entre as duas manifestações poéticas. Pois enquanto, como o mesmo Horácio o afirma, os gêneros se aproximam no que, aristotelicamente, chamaríamos matéria de imitação, os distingue um critério um tanto mais decisivo que a simples transposição da cadência de versos: um contrastante modo de imitação e as consequentes possibilidades conferidas a cada gênero por esses modos diversos. Pois o aparato técnico implicado na atualização da estrutura dramática da comédia - atores, figurino, cenário etc. - desvincula de maneira mais imediata a encenação e a realidade empírica; por outro lado, o discurso que aponta e censura o vício, sendo proferido com o envolvimento de uma voz pessoalizada, caminha em sentido inverso, aproximando-se da empiria pela semelhança que guarda com o exercício público da palavra por parte do orador.

A partir dessas considerações, chegamos à sátira de Juvenal, foco efetivo de nosso estudo. No contraste entre Horácio e Juvenal, chama atenção a presença, um tanto quanto maior, no primeiro, de uma autorreflexividade em relação ao gênero poético cultivado. No entanto, ainda que reduzida em Juvenal, a autorreferência integra convencionalmente a primeira sátira do poeta, na qual se enuncia um programa seguido pelo menos em seus dois primeiros livros (nas sátiras de 1 a 6, portanto). Não há, entretanto, em meio às passagens programáticas do poema, nenhuma referência ao riso como elemento constituinte da sátira. O que se vê, ao contrário, é a assunção, por parte da voz que enuncia, da preponderância da ira como emoção central implicada na construção dos versos, uma ira suscitada pelas torpezas que dominam a Roma das sátiras e que impelem o poeta a responder. Não por acaso, no primeiro bloco do poema, em que Juvenal explicita e defende seu pertencimento genérico, aparecem palavras que associam diretamente a composição da sátira à ideia de resposta à injúria, de punição, como nos seis versos iniciais: 


\section{Semper ego auditor tantum? numquamne reponam uexatus totiens rauci Theseide Cordi? inpune ergo mihi recitauerit ille togatas, hic elegos? inpune diem consumpserit ingens Telephus aut summi plena iam margine libri scriptus et in tergo necdum finitus Orestes? (Juv. 1.1-6)}

\section{Sempre apenas ouvir? Nunca responderei, eu, tão farto da Teseida do rouco Cordo? Então lerá pra mim, impune, este togadas, outro elegias? E um dia esvairá, impune, ingente Télefo, ou, frente e verso do rolo já escritos, e 'inda assim não findo, um Orestes?}

Em tais versos, nos quais Juvenal rechaça os gêneros poéticos que dizem pouco ou nada sobre a realidade empírica - razão por que são preteridos pelo poeta em favor da sátira - e que, apesar, ou mesmo em decorrência disso, parecem ser excessivamente cultivados na Roma de seu tempo, fica explícito o caráter punitivo que o poeta pretende para sua sátira. Novamente, é relevante o vocabulário empregado - auxiliado pela estrutura sequencial de perguntas retóricas cujas respostas são o ato mesmo de sua enunciação. O verbo repono, no sentido de "colocar de volta", "devolver", aparece, no primeiro verso, em clara antítese a "permanecer sempre somente um ouvinte", postura em que o poeta é "abusado" pela "Teseida do rouco Cordo". Permanecer em silêncio, portanto, é, aqui, equivalente a deixar impunes os poetas épicos, cômicos, elegíacos e trágicos que perturbam o satirista. Dessa forma, a ação que o verbo repono denota é essencialmente punitiva, no contexto, na medida em que, como forma de vingança, o que o poeta "devolve" é a injúria que sofre na postura de ouvinte passivo. A deflagração do discurso satírico é, aqui, como notou Freudenburg (2001, 212), representada como resultante da irritação acumulada não apenas pela frequência das recitações ou da má qualidade da poesia que nelas figura, mas principalmente pelo fato de que simplesmente ouvi-las significa, para o poeta, calar a sátira, constatando o quanto a poesia esvaziou-se de algo relevante a ser dito.

É claro, por um lado, que essa indignação inicialmente fora de lugar constitui uma maneira artificiosa - e efetivamente jocosa, na troça que se encena aos poetas contemporâneos - de posicionamento genérico por parte do poeta e que, por outro, sua ira encontrará alvos mais merecedores ao longo do poema. Importa, aqui, a associação entre a composição da sátira e a aplicação de um castigo, bem como a maneira como tal associação ajuda a construir o caráter do satirista, na medida em que é dever do virtuoso castigar o vício. No entanto, na construção mesma de sua indignatio e na descrição da 
ira que o vício lhe suscita - ira que lhe arde o fígado (Juv. 1.45) o satirista põe em xeque seu caráter de vir bonus. Cícero (De Off. 1.66- 67) define como virtude dos grandes homens a indiferença às coisas externas, o que só se pode conseguir quando se tem a retidão moral como o único bem e quando se é livre de quaisquer paixões. Conta, ainda, como características dos homens virtuosos, moderação e temperança, as quais o discurso indignado do satirista em Juvenal abandona declaradamente. Cícero reconhece que é dever do homem justo punir o vício visando ao bem do estado, mas ressalta que:

Cavendum est etiam ne maior poena quam culpa sit et ne isdem de causis alii plectantur, alii ne appellentur quidem. prohibenda autem maxime est ira puniendo; numquam enim iratus qui accedet ad poenam mediocritatem illam tenebit, quae est inter nimium et parum, quae placet Peripateticis et recte placet, modo ne laudarent iracundiam et dicerent utiliter a natura datam. Illa vero omnibus in rebus repudianda est optandumque, ut ii, qui praesunt rei publicae, legum similes sint, quae ad puniendum non iracundia, sed aequitate ducuntur. (Cic. De off. 1.89)

Deve-se cuidar, também, para que o castigo não seja maior do que a culpa e para que uns não sejam punidos em razão das mesmas causas pelas quais outros não sejam sequer chamados [a prestar esclarecimento]. Deve-se vetar acima de tudo a ira na aplicação de um castigo; pois nunca um iracundo que proceda à aplicação de uma pena terá aquela moderação que está entre o excesso e a falta, e que, com razão, é do agrado dos peripatéticos, ainda que eles, infelizmente, louvem a ira e digam que nos foi dada pela natureza. Ela, na verdade, deve ser repudiada em todas as ocasiões e se deve sempre desejar que aqueles que estão à frente dos assuntos públicos sejam semelhantes às leis, que, para punir, não são guiadas pela ira, mas pela justiça.

Dessa forma, Juvenal explora, em sua sátira, uma tensão constituinte do próprio caráter da persona satírica. ${ }^{11}$ Nessa tensão, a voz do satirista ao mesmo tempo aproxima-se e afasta-se do êthos cuja construção deve ser alvo do orador. Exemplo disso é o fato de o arroubo de indignação advindo da enumeração constante dos diversos vícios que cercam o satirista ter início no momento exatamente posterior àquele em que o poeta enuncia sua filiação a Lucílio nos seguintes termos:

cur tamen hoc potius libeat decurrere campo, per quem magnus equos Auruncae flexit alumnus, si uacat ac placidi rationem admittitis, edam. (Juv. 1.19-21)

Então direi por que é melhor correr por este campo onde o aluno de Aurunca os seus cavalos domou, se com vagar e plácidos me ouvirdes.

\footnotetext{
${ }^{11}$ Sobre o assunto, cf. o ensaio de William Anderson 1982, 263-91.
} 
Duas palavras, no contexto, nos auxiliam a percepção da tensão a que nos referimos. É significativo o emprego do adjetivo placidus (placidi, Juv. 1.21), estado de espírito com que Juvenal espera que os interlocutores ouçam o que tem a dizer, bem como do substantivo ratio (rationem, Juv. 1.21), com o qual o poeta se refere propriamente àquilo que dirá. Tais palavras têm implicações importantes por pertencerem a um campo semântico em tudo oposto à natureza do discurso indignado que dá prosseguimento ao poema. Ao empregá-las, o poeta explora ironicamente o absurdo do pedido que faz à audiência - ouvir plácidos a um argumento irado - bem como a paradoxal nomeação de seu discurso pela palavra ratio, que, não obstante possa ser entendida simplesmente na acepção de "argumento", ainda denota algo que seja racionalmente ordenado. Explora-se, portanto, a racionalidade característica do vir bonus e o abrupto abandono dessa mesma racionalidade em favor da indignação que, falhando a natureza, trata de compor o verso. É importante que recordemos, ainda, que a própria motivação da indignada enumeração dos vícios feita pelo poeta é, tal qual são muitas das actiones desempenhadas por oradores, de natureza persuasiva - tratar-se-ia do caso "por que razão é preferível escrever sátira a outros gêneros ou a nada escrever?" Em prol de sua causa, Juvenal apenas não usa a razão que promete à audiência e, se persuade, o faz pelo impacto da indignatio sobre seus plácidos ouvintes.

Pelo próprio modo de enunciação do gênero poético, bem como pelo procedimento de construção da imagem de um virtuoso cujo domínio das próprias forças a ira lhe aliena, a voz do satirista em Juvenal se aproxima e se afasta daquela do orador que procede ao vitupério com vistas ao bem comum. Este estudo, situado como ponto de partida de uma pesquisa maior sobre as sátiras de Juvenal, aponta um caminho interessante para a análise desses poemas: a construção conflituosa da voz enunciadora e seu caráter ambíguo, como elementos que possam favorecer a relação entre a sátira e o humor.

\section{REFERÊNCIAS}

Anderson, William 1982. Essays on Roman Satire. Princeton: Princeton University.

Citroni, Mario. 2010. "Musa pedestre". In O espaço literário da Roma antiga. Volume I: a produção do texto literário, edited by G. Cavallo, P. Fedeli and A. Giardina. Trad. D. P. Carrara e Fernanda M. Moura, 329-60. [1ª edição original: 1989]. Belo Horizonte: Tessitura.

Clausen, W. V. 1992. Persius et Iuuenalis: Satorae. Edidit brevique adnotatione critica denvo instrvxit [1ª edição:1959]. New York: Oxford University. 
Dupont, Florence. 1997. "Recitatio and the reorganization of the space of public discourse." In The Roman cultural revolution, edited by T. Habinek e A. Schiesaro. New York: Cambridge University.

Freudenburg, Kirk. 2001. Satires of Rome: threatening poses from Lucilius to Juvenal. U.K.: Cambridge University.

Freudenburg, Kirk, ed. 2005. The Cambridge Companion to Roman Satire. Cambridge University Press.

Glare, P. G. W. 1968. Oxford Latin Dictionary. London: Oxford University.

Hansen, João Adolfo. 2011. "Anatomia da sátira". In Permanência clássica: visões contemporâneas da Antiguidade greco-romana, editado por M. Thamos e B. V. G. Vieira, 145-69. São Paulo: Escrituras.

Marques Júnior, Ivan N. 2008. O riso segundo Cícero e Quintiliano: tradução e comentários de De oratore, livro II, 216-291 (De ridiculis) e da Institutio oratoria, livro VI, 3 (De risu). Dissertação de Mestrado. Universidade de São Paulo.

Miller, Walter. 1931. Cicero: On moral duties. Latin text with facing English translation. Cambridge, M.A.: Harvard University.

Sousa, Eudoro de. 1994. Aristóteles: Poética. Tradução, introdução, comentário e apêndices. Lisboa: Imprensa Nacional - Casa da moeda.

Vollmer, F. 1912. Horatius: Q. Horatii Flacii Carmina. Leipzig: Teubner.

Title. The construction of speaker's ethos in Juvenal's Satires.

Abstract. The paper starts from the idea that Latin satire, since it is a form of poetic expression markedly personalized, so as for its moral purpose of reproaching vice, has similarities with the orator's speech. Therefore, as is the case in the oratorical practice, satire demands the construction of an uttering voice that, in Juvenal, approaches and deviates from the êthos the orator constructs for himself in his speech. The paper discusses that procedure, associating it to the pertinence of laughter as an integrating element of satire as a poetic genre.

Keywords. Juvenal; Latin satire; poetic voice; laughter. 